\title{
Computerreservierungssysteme (CRS) und Passenger Name Records (PNR)
}

\section{Computerreservierungssysteme}

Ein erheblicher Teil der Buchungen von Reisen (Hotelübernachtungen, Flüge, Kreuzfahrten, Mietwagen, Bahnreisen etc.), die von Reisebüros und Online-Portalen weltweit vermittelt werden, erfolgen heute in zentralen Computerreservierungssystemen (CRS). Sie bieten Reisebüros den Zugriff auf aktuelle Preise und verfügbare Plätze und sorgen für eine unmittelbare Platzreservierung beim jeweiligen Anbieter. Durch die Online-Anbindung von Reisebüros, Reise-Portalen und -Anbietern an ein zentrales CRS vereinfacht sich der Informationsfluss erheblich: Angebote und Preise sind ständig aktuell und lassen sich automatisch an die Nachfrage anpassen, und Buchungen erfolgen in Echtzeit. Insbesondere für Flugbuchungen erlauben CRS den Passagieren den Selbstausdruck von Tickets, sowohl über das Internet als auch an speziellen Terminals.

CRS sind hoch komplexe Systeme, die für eine Vielzahl von Beteiligten eine extrem hohe Zahl an Transaktionen zu bewältigen haben (Buchung, Stornierung, Auskunft, Platzreservierung, ...) und riesige Datenmengen verarbeiten. Der Zugriff aus den Reisebüros erfolgt über einheitliche Masken; Online-Portale greifen über definierte Schnittstellen auf die Reservierungssysteme zu.

Die Betreiber eines CRS rechnen die Kosten buchungsbezogen mit den Reiseanbietern ab und übernehmen teilweise auch die Verrechnung von Vergütungen der Reisebüros. Den weltweiten Markt teilen sich im Wesentlichen vier CRS-Anbieter: Amadeus, Galileo, Sabre und Worldspan.

\section{Passenger Name Records}

Die Buchungsdaten werden in „Passenger Name Records“ (PNR) gespeichert und verarbeitet. Diese enthalten die folgenden personenbezogenen Buchungsinformationen [1], die in einigen Staaten (darunter die USA und GB) gesetzlich vorgeschrieben sind:

- Datum, an dem der PNR erstmals angelegt wurde sowie nachfolgende Änderungen

- Flugspezifische Daten:

- Flugtage und -strecken (Segmente)

- Flugnummern

- Flugzeiten (Ortszeiten)

- Flugdauer

- Fluggerät (Typenbezeichnung)

- Buchungsklasse (Flugtarif)

- Vor- und Zuname des oder der Passagiere

- Wohnadresse und Telefonnummer eines oder mehrere Passagiere

- Adresse und Telefonnummer am Zielort

- Zahlungsart (z. B. eine Kreditkartennummer mit Ablaufdatum)

- Rechnungsanschrift

- Vielflieger-Eintrag

- Name der Buchungsagentur (Reisebüro, Firmenbuchungsstelle u. ä.)

- Sachbearbeiter der Buchung

- Codeshare-Information (falls eine andere Fluggesellschaft den Flug ausführt)

- Reisestatus des Passagiers (abgeflogene Strecken)

- Informationen über die Splittung einer Buchung (falls ein oder mehrere Passagiere getrennt werden, weil sie beispielsweise eine andere Strecke fliegen möchten)

- E-Mail-Adresse

- allgemeine Bemerkungen

- Informationen über Flugscheinausstellung (Ticketing)

- Daten zum Flugtarif

- Daten der Flugscheinausstellung

- Sitzplatzinformationen (Status, Sitzplatznummer)

- Nummern der Gepäckanhänger

- Historie über nicht angetretene Flüge (no show)

- Fluggäste mit Flugschein, aber ohne Reservierung (go show)

- spezielle Serviceanforderungen (z. B. Sonderwünsche zum Essen)

- Information über den Auftraggeber
- alle Änderungen des PNR mit Datum, Uhrzeit und Aktion (PNR-History)

- Zahl der Reisenden im PNR

- etwaige APIS-Informationen (Advance Passenger Information System)

- automatische Tarifabfrage

- ggf. alle zu einer Mietwagen- oder Hotelbuchung gehörenden Daten

Jeder PNR erhält nach der Erstellung einen eindeutigen Buchungscode, den so genannten „Record Locator". Unter diesem Code kann der Mitarbeiter eines Reisebüros die Buchungsdaten "seiner" Kunden einsehen und bearbeiten. Auch ein Passagier kann mit diesem Buchungscode beispielsweise seine Flugbuchungsdaten über die Webseite der Fluglinie einsehen.

\section{Datenschutz}

Die Verarbeitung der PNR durch die Betreiber der Reservierungssysteme erfolgt im Auftrag der Reiseanbieter. Sie unterliegen in Europa neben der EG-Datenschutzrichtlinie auch den Bestimmungen der EG-Verordnung Nr. 80/2009 des Europäischen Parlaments und des Rates vom 14.01.2009 über einen „Verhaltenskodex in Bezug auf Computerreservierungssysteme" [2]. Dieser am 29.03.2009 in Kraft getretene Code of Conduct legt neben Auskunftspflichten und Sicherheitsanforderungen insbesondere die Pflicht zur Offline-Archivierung von Einzelbuchungen innerhalb von drei Tagen nach Abwicklung des letzten Teils einer Einzelbuchung (,last flown segment") und die Löschung innerhalb von drei Jahren fest.

Quellen

[1] Wikipedia: Computerreservierungssystem (CRS) und Passenger Name Record (PNR); http://de.wikipedia.org/wiki/Passenger_Name_Record und http://de.wikipedia.org/wiki/ Computerreservierungssystem (08.03.2010)

[2] Europäisches Parlament und Europarat: Verhaltenskodex in Bezug auf Computerreservierungssysteme (Codes of Conduct); EG-Verordnung Nr. 80/2009, Amtsblatt der EU vom 04.02.2009, L 35/47-55. http://eur-lex.europa. eu/LexUriServ/ LexUriServ.do?uri=0J:L:2009: 035:0047:0055:DE:PDF 